\title{
Regulación blanda, negociación y aprendizaje en los Comités de Empresa Europeos en las empresas multinacionales químicas alemanas en España
}

\author{
Manuel AHEDO SANTISTEBAN* \\ Universidad del País Vasco (UPV-EHU) y \\ Grupo ASO Universidad Rovira i Virgili (URV) \\ manuel.ahedo@ehu.es
}

Recibido: 1-07-2009

Aceptado: $17-12-2010$

\begin{abstract}
RESUMEN
La Directiva de la Unión Europea (UE) de Comités de Empresa Europeos (CEEU) de 1994 es conceptualizada como una regulación blanda que deja abierta la posibilidad de negociación, aprendizaje, y evolución. El artículo analiza los factores internos y externos en las dinámicas de evolución de los CEEU en tres empresas químicas alemanas. Los factores internos se refieren a las dinámicas organizativas de cada CEEU y del propio grupo multinacional, y los externos son relativos al sistema sindical y de representación de empleados del país de la matriz y de la filial, así como a las particularidades del sector. Con datos secundarios y entrevistas se analizan los aspectos comunes y diferentes de los CEEU, dentro del contexto regulativo de la UE. Los factores internos generan diferenciación, y los factores externos llevan los CEEU en una dirección similar desde una asimetría estructural inicial hacia unas relaciones más dinámicas e interactivas.
\end{abstract}

Palabras clave: glocalidad, Empresas Multi-Nacionales, Europeización, Sector Químico

Soft regulation, negotiation and learning in the European Work Councils of the German chemical Multi-Nationals in Spain

\begin{abstract}
The 1994 European Union (EU) Directive on European Work Councils (EWC) is conceptualized as a soft regulation that leaves open possibility for negotiation, learning, and evolution. The paper analyzes how internal and external factors influence the evolution dynamics of EWC in three chemical German multina-

*Manuel Ahedo es Profesor Ayudante Doctor de Sociología de la Universidad del País Vasco (UPV-EHU) y miembro del grupo de investigación Análisis Social y Organizativo (ASO) de la Universidad Rovira i Virgili (URV). Entre sus últimas publicaciones destacan artículos en revistas nacionales e internacionales sobre desarrollo local y regional, sistemas de innovación (Arbor), políticas de cluster (European Planning Studies, European Urban and Regional Studies), PYMEs e innovación (Transfer), y Empresas Multi-Nacionales (Revista Internacional de Organizaciones), y política pública comparada (Comparative Sociology).
\end{abstract}


tional enterprises. The internal factors relate to the organizational dynamics of each EWC and the multinational group. The external factors look at the institutional or societal aspects of labour unionism and employee representation at both headquarters and subsidiary countries. Based on secondary data and interviews with key informants, the common and different dynamics of the EWC are analyzed, within the European Union's institutional and regulatory context. While the internal factors foster a differentiation process between them, the external factors move the EWC in a similar direction from initial structural asymmetries towards more dynamic and interactive relations.

Key words: glocality, multi-national corporations, europeanization, chemical sector

\section{REFERENCIA NORMALIZADA}

Ahedo Santisteban, M. (2012). Regulación blanda, negociación y aprendizaje en los Comités de Empresa Europeos en las empresas multinacionales químicas alemanas en España. Cuadernos de Relaciones Laborales Vol. 30, núm.1, p. 163-184.

SUMARIO: Introducción. 1. Los factores internos y externos en el análisis de los comités de empresa europeos (ceeu). 1.1. Factores internos: comités de empresa y organización del grupo empresarial. 1.2. Factores externos o institucionales: país y sector. 1.3. La dimensión europea: directivas CEEU y diálogo sectorial. 2. Las multinacionales químicas alemanas en Tarragona. 3. El contexto del encuentro sindical y laboral alemán-español. 3.1 El sistema español y catalán. 3.2 El sistema alemán. 3.3. La recepción de la directiva CEEU por los sindicatos españoles. 4. Creación y evolución de los CEEU. 5. Análisis. 6. Conclusiones. Bibliografia.

\section{Introducción}

El proceso de integración de la Unión Europea (UE) ha ido creado nuevas posibilidades para la relación, interacción y negociación de las entre los actores empresariales y sindicales en las Relaciones Laborales (RRLL) a nivel europeo. La globalización económica y productiva ha estado liderada por las Empresas MultiNacionales (EMN). La Directiva de los Comités de Empresa Europeos (CEEU) de Septiembre de 1994, transpuesta en el 1996, ha sido actualizada en el 2008-9, cuyo proceso de transposición nacional termina en Junio 2011. Esta Directiva regula la creación de un órgano de representación a nivel europeo para empresas que tienen más de 1000 empleados en total y más de 150 en al menos dos países de la UE. Esta Directiva ha sido considerada como uno de los mayores desarrollos en el proceso de europeización de las RRLL, junto a lo que la Directiva del 2000 sobre el Estatuto de la Sociedad o Empresa Europea establece respecto a la representación de los empleados y al comité de empresa. La Directiva de CEEU se puede conceptualizar como un avance más en el desarrollo de la regulación blanda en la UE en las últimas décadas, en oposición a la tradicional regulación dura. El mayor paso en esta dirección fue la adopción del Método Abierto de Coordinación en el 2000 como nuevo instrumento de regulación y gobernanza de la UE. La regulación blanda, argumentan Lecher, et al. (2002), promueve una Europeización a través de la interacción y la negociación entre los agentes y actores involucrados, a la vez que posibilita directa e indirectamente el aprendizaje mutuo. 
La creación de los CEEU ha tenido varias etapas. ${ }^{1}$ En una primera etapa, antes de la aprobación en Septiembre de 1994, y según datos de Kerckhofs (2002), se habían constituido 49 comités u órganos similares en 46 empresas. En EMN de capital francés se crearon 17 (12 por acuerdo formal) y en EMN de capital alemán 14 (9 por acuerdo formal). El mayor desarrollo en Francia se explica en parte al efecto originado por la segunda Ley Auroux de 1982 que establecía el comité de empresa de grupo, y su rápida aplicación en grandes empresas con participación pública. En una segunda etapa, hasta septiembre de 1996, fecha límite para la transposición de la Directiva en las normas legales de cada país, se crearon unos 400 CEEU. Este alto número se debe a que estos comités creados de forma voluntaria iban a quedar exentos de la Directiva, y cabe destacar la fuerte incorporación de EMN alemanas al proceso. En una tercera etapa, después del 1996 el número de CEEU crece de forma más paulatina. Según los datos de la Confederación Europea de Sindicatos (CES), que ha sido la principal institución en la recogida de esta información, en el 2002 el número total de CEEU era de 639, de un total de unas 1865 empresas que se consideraban afectadas por la Directiva, en el 2008 eran aproximadamente 900, y en el 2010 el número total de CEEU es de 960. Queda por ver si la renovada Directiva del 2008-9, transpuesta en el 2011 tiene algún efecto. Por países, Alemania, Reino Unido y Francia son los países con mayor número de EMN afectadas por la Directiva, y presentan diferentes niveles de creación de CEEU. Para datos del 2002 (Kerckhofs, 2002), en Alemania había 100 CEEU; en el Reino Unido 93, y en Francia 65. Juan (2008) ofrece datos sobre la corta implantación de los CEEU en empresas internacionales de capital español.

El complejo químico de Tarragona, en el Sur de Cataluña, produce el $44 \%$ del total de los plásticos producidos en España, y supone aproximadamente el 25\% de la industria química española. ${ }^{2}$ El complejo de Tarragona se caracteriza por una alta presencia de filiales pertenecientes a grandes empresas de capital extranjero. De las aproximadamente 30 empresas en el complejo, unas dos terceras partes del total son de capital extranjero, principalmente europeo. Desde los años 60 ha habido 3 filiales de 3 grandes EMN químicas mundiales con origen en Alemania (Basf, Bayer y Hoescht-Clariant). En las décadas EMN alemanas, además de su fuerte peso en la industria química mundial y en Europa. En las décadas de los años 80 y 90 Alemania y Suiza se convirtieron en la emergente región líder de la química en el mundo, con el liderazgo de las EMN químicas alemanas. En los últimos años nuevos grupos empresariales químicos se han incorporado a la elite mundial del sector, provenientes de fuertes procesos de adquisición y compra, como INEOS, Sabic y Evonik, y por empresas e inversores procedentes de países emergentes, como Rusia (LyondellBasell), Sabic de Arabia Saudi, Sinopec de China y Formasa Plastics de Taiwan. Los

\footnotetext{
${ }^{1}$ Ver Köhler y González-Begega (2004) con datos hasta el 2002.

${ }^{2}$ Cataluña representa el $45 \%$ de la producción del sector químico español y un $50 \%$ de les exportaciones.
} 
tres casos de CEEU y EMN analizados son considerados representativos, importantes y singulares. Son representativos por el fuerte peso de los representantes alemanes en los CEEU en Europa. Se calcula que la presencia de representantes de trabajadores alemanes en todos los CEEU constituidos en Europea es de aproximadamente dos tercios de todos los representantes, y en el caso de la química su presencia es aún más alta y más importante ya que ocupan muchas de las oficinas centrales de los CEEU. Son importantes dado el peso de las EMN alemanas en la química europea. Y son singulares debido a los rasgos específicos del sector químico.

El artículo analiza el surgimiento y evolución de los CEEU en tres EMN de origen alemán (Basf, Bayer y Clariant), desde su proceso de constitución a inicios de los años 90 hasta el 2008. A través de un análisis cualitativo, con información secundaria y entrevistas, se analiza la relación entre los factores internos y externos que afectan al surgimiento y evolución de los tres CEEU. ${ }^{3}$ En la sección II se presenta el marco analítico de los factores internos y externos, que sirven para entender las características comunes y diferentes en la evolución de los tres CEEU. La sección III ofrece algunos datos relativos al complejo químico de Tarragona y las tres EMN químicas alemanas. En la sección IV se analiza el contexto previo a la creación de los CEEU, en donde tiene lugar el encuentro laboral entre la matriz alemana y las filiales españolas. En la sección V se describe la creación y la evolución de los tres CEEU. Finalmente, la sección VI analiza cómo han influido los factores internos y externos en la evolución de los CEEU, para terminar con las conclusiones en la sección VII.

\section{Los factores internos y externos en el análisis de los comités de empresas europeos (ceeu)}

Los CEEU han sido objeto de estudio de una amplia literatura por parte de investigadores académicos. Se pueden discernir tres tipos de enfoque: a) el crítico, especialmente por el entorno sindical de la Confederación Europea de Sindicatos (CES), en colaboración con el Instituto de Investigación del CES (ETUI), que además han trabajado por reunir y armonizar información sobre los CEEU creados; ${ }^{4}$ b) un enfoque posibilista y pragmático que enfatiza las posibi-

\footnotetext{
${ }^{3}$ El análisis se hace en base a datos secundarios diversos, y a datos primarios obtenidos en 8 entrevistas en profundidad: 4 con representantes en los comités de empresa europea de las 3 EMN alemanas analizadas, y 4 con responsables de las federaciones industriales de la CCOO y UGT de Tarragona y de Cataluña (algunas entrevistas fueron realizadas por alumnos de la asignatura Sistemas de Relaciones Laborales Comparadas para trabajos de la asignatura durante el curso 2007-2008).

${ }_{4}^{4}$ Como la base de datos sobre los acuerdos de CCEU (http://www.ewcdb.eu), que centraliza la base de datos del European Trade Union Institute (ETUI), recogidos en publicaciones más o menos periódicas como la de Kerckhofs 002).
} 
lidades y potencialidades; y c) un enfoque analítico que ha analizado la evolución y los tipos de CEEU.

En el enfoque crítico, se indica que la realidad no ha respondido a las altas expectativas que despertó la Directiva (Wills, 2000; Fitzegerald y Stirling, 2004). Se critica la laxitud y excesiva flexibilidad normativa de la Directiva, al no establecer de forma clara la organización interna, ni cuestiones importantes sobre el funcionamiento y las funciones del CEEU, dando lugar a una alta variedad de CEEU. Esta literatura, liderada por publicaciones de la CES, a través por ejemplo de la revista del ETUI Transfer (Waddington y Kerckhofs, 2003), se ha mostrado crítica con el desarrollo de la Directiva, y ha reclamado durante mucho tiempo una reformulación y profundización formal y normativa de la misma. Este enfoque prefiere las ventajas de la regulación dura en la UE, es decir, la tradicional regulación más vinculante y con acuerdos sustantivos fuertes, a pesar de los largos procesos de negociación de consensos en la UE que este tipo de regulación conlleva, como es el caso de la Directiva de Sociedad Europea del 2001, proceso que se inició en los años 70.

En el enfoque posibilita, algunos investigadores han enfatizado la potencialidad de los CEEU como mecanismo de relación, interacción, y posibles intercambios de información, experiencias, aprendizaje, etc., (por ejemplo, Kristensen y Zeitlin, 2005). Este enfoque más posibilista y pragmático, aún reconociendo que muchos CEEU han sido instrumentalizados por los equipos gestores de las EMN para sus procesos de reestructuración o de competencia entre regímenes, resaltan el corto proceso de aprendizaje en los CEEU para poder crear públicos o colectivos de interés respecto a las EMN, tanto general como individuales. Un estudio que recogía la percepción de los participantes en CEEU en los países nórdicos (Knudsen y Sorensen, 2000) indicaba la dificultad del trabajo en los CEEU, aceptaba su posible potencialidad, y apuntaba a la necesidad de formación para una participación más efectiva en los CEEU, y en concreto un mayor conocimiento sobre los diferentes sistemas nacionales laborales, tanto europeos como internacionales. La regulación blanda es más fácil de ser acordada, y a pesar de sus indefiniciones y deficiencias, su carácter abierto y flexible para su reflexión y renovación, permite una evolución en la negociación y aprendizaje.

En el enfoque más analítico se han investigado los factores que explican el funcionamiento y los tipos de CEEU. Se pueden destacar tres estudios. Primero, en un estudio cualitativo de 41 CEEU (EIRO, 2004) se concluye que los factores fundamentales son la historia de la empresa y las relaciones laborales de la empresa, junto la influencia de las relaciones laborales nacionales y especialmente si la empresa tiene o no experiencia en la representación de empleados al nivel de empresa. Segundo, Lecher, et al. $(2001,2002)$ estudian cualitativamente un número reducido de casos, e indican tres principales factores claves: a) las relaciones entre los representantes de los diferentes países; b) la relación entre los representantes y su electorado; y c) la relación de los representantes con los sindicatos locales y sectoriales y el movimiento sindical nacional e internacional; y proponen un ciclo evolutivo del CEEU en cuatro tipos o estadios: simbólico, de servicios (información y ayuda mutua), con un proyecto orientado (desarrollo sistemático y estratégico de sus 
operaciones internas y estructuras de comunicación), y participativo (foro para la articulación y representación de los intereses de los empleados, para la consulta y para la negociación). Para la fecha de su estudio, la mayoría de los CEEU se situaban en los primeros dos tipos o estadios, y son pocos los casos que habían llegado al tipo participativo. Finalmente, Bicknell (2006) analiza el papel de los representantes alemanes en los CEEU, y propone la existencia de tres tipos de CEEU: etnocéntrico, policéntrico y eurocéntrico. Mientras el tipo etnocéntrico sería la situación tradicional de muchos comités de empresa, en el que domina la lógica y el interés alemán, el tipo policéntrico sería el más desarrollado al mantener la centralidad alemana pero aumentando y extendiendo la participación a otros representantes de otros países europeos. El tipo eurocéntrico, que pivotaría sobre una fuerte identidad europea, sería el más difícil de conseguir. Para Bicknell, hay tres factores que influyen para que un CEEU avance de un tipo o a otro: la estructura de la empresa o grupo empresarial, el papel del sistema de relaciones laborales dominante de la oficina central, y las habilidades individuales y características nacionales de los actores clave. Es decir, junto a la importancia de las relaciones y comunicación inter-personales para la construcción de confianza e identidad, la investigación tiende a subrayar los factores internos-organizativos y externos-institucionales.

En base a estas y otras contribuciones recientes de la literatura especializada (Marginson y Sisson, 2006; Whittall, Knudsen y Huijgen, 2007; Waddington, 2011), se propone un enfoque multi-dimensional integrando con una clara diferenciación las dos dimensiones principales en el análisis de las EMN: los factores internos, de carácter más organizativo, y los factores externos o institucionales, dentro del contexto institucional y regulativo de la Unión Europea.

\subsection{Factores internos: comités de empresa y organización del grupo empresarial}

En lo referente al modelo organizativo de los CEEU, según datos de la CES para el 2002, recogidos en Kerckhofs (2002), el 37\% seguía el modelo alemán (o nórdico) con la única presencia de empleados, y el $63 \%$ se orientaba por el modelo francés de participación conjunta de empleados y dirección. Esto indica una cierta tendencia hacia la co-presencia de empleados y dirección en los CEEU, incluso en CEEU de EMN de matriz alemana o nórdica. Queda por ver si la aplicación de la nueva Directiva del 2008-09 trae cambios en la composición de los CEEU. En lo que respecta a la organización del grupo empresarial, de cara al CEEU es importante la relación entre la matriz y las filiales dentro del grupo empresarial, es decir, el tipo de organización, estructura y gestión de sus redes de filiales. Sobre esta cuestión la literatura ha desarrollado varias tipologías. Köhler y González-Begega (2004), recogen la clasificación de Barlett y Ghoshal con sus 4 tipos básicos de EMN según su modelo de organización: multinacional, global, internacional, y transnacional. La correlación entre estos modelos y el país de origen de la EMN ha sido una cuestión difícil de ser observada, a medida que las EMN se han ido internacionalizado y creciendo. Se ha observado que las EMN, independientemente de su país de origen, han desarrollado formas diferenciadas de organización dentro de marcos y tendencias globales similares. Por lo tanto, es de esperar que los CEEU de 
empresas químicas alemanas presenten una combinación de aspectos organizativos derivados tanto del origen alemán de la EMN, como de las propias dinámicas de la empresa.

\subsection{Factores externos 0 institucionales: país y sector}

El factor país, tanto de origen o de la matriz, como receptor o de la filial, se refiere a la variable institucional nacional. Los estudios de relaciones laborales comparadas han indicado las constantes diferencias entre las naciones-estado en el funcionamiento de las RRLL, en aspectos como el sistema de organización de los empleados, las formas de representación, la tradición legal o jurídica de regulación laboral, la tradición bipartita o tripartita de negociación colectiva, etc. (Poole, 1986; Bean, 1994; y Ruysseveldt y Huiskamp, 1995). En este sentido, se asume que las instituciones y regulaciones nacionales del país de origen de la EMN, y por ende del CEEU, imprimen sus tradiciones organizativas en la gestión productiva y laboral del grupo y de las filiales. Según Waddington (2011), la articulación entre el CEEU y las organizaciones sindicales locales y nacionales es clave para entender los CEEU como instituciones de información y consulta, y como medios para influir en las decisiones del equipo de gestión. Respecto al efecto del país receptor, la localización de la producción es una variable importante en la organización interna de una EMN. La decisión de localización de la producción es más relevante que la actividad comercial, ya que puede buscar beneficiarse de alguna ventaja institucional o societal de una localidad o país concreto. La variable país, tanto de la matriz como de la filial, es una variable clave en el funcionamiento de un CEEU.

La variable sectorial ha sido también una dimensión presente en muchos estudios comparados de economía política, principalmente en la perspectiva de los sistemas sociales de producción (Hollingsworth y Streeck, 1994). La variable sector asume que una similar tecnología, organización de la producción y una concurrencia del mercado conlleva ciertas similitudes en el funcionamiento de las empresas de un mismo sector. Cada sector presenta su particular forma de organizar el trabajo, con una mayor o menor integración del proceso y cadena de valor, y de posibles relaciones interdependientes entre filiales. Así, en las industrias de bienes de equipo, maquinaria o manufacturas, se suele dar una alta interrelación entre filiales, a través de la cadena de suministro de componentes, sistemas, etc. Por el contrario, en el sector de la química de materiales (plásticos, etc.) se encuentran altos niveles de integración vertical, y tendencias a semi-oligopolios o de alta concentración empresarial. Según datos de la Federación Sindical de la Química en Europa, las PYMEs con menos de 250 empleados suponen una tercera parte del empleo en el sector químico, mientras que en toda la industria manufacturera supone casi un $60 \%{ }^{5}$

${ }^{5}$ Ver el Capítulo 1 de Purcalla, et al. (2010) para una descripción de las limitadas relaciones inter-empresariales de suministro y provisión de las empresas químicas del complejo de Tarragona. 


\subsection{La dimensión europea: directivas CEEU y diálogo sectorial}

La revisión de la Directiva del 2008-2009 recoge algunas de los aspectos criticados y supone algunos avances dentro de la línea avanzada en la Directiva de Sociedad Europea del 2001, transpuesta en toda la UE-25 en Enero del 2007. ${ }^{6}$ La nueva directiva revisada de CEEU del 2008-09 avanza principalmente en los derechos de información y consulta (pero no en el de participación), en el papel de los sindicatos (pero sin derechos), en la posibilidad de creación de comités específicos y de seguimiento con mandato de representación colectiva, y en el derecho a la formación para los miembros del CEEU. Continúa también facilitando el desarrollo del modelo de co-presencia empleados y directivos en los CEEU, aunque también puede estimular un refuerzo de la parte de los empleados y sindical. Es decir, la Directiva renovada sigue dentro del modelo de regulación blanda con algunas cuestiones más clara y duramente reguladas.

El proceso de europeización de las relaciones laborales a nivel sectorial ha sido un proceso lento y difícil, y su desarrollo formal y sustantivo es todavía bastante bajo, tal y como recogen Köhler y González-Begega (2007b). Otros autores indican las potencialidades formales e informales del nivel sectorial para la europeización de las RRLL (Keller, 2003; Marginson y Sisson, 2006). Ante la falta de interés de las asociaciones empresariales sectoriales, las federaciones sectoriales de la CES han desarrollado múltiples iniciativas de coordinación sindical trans-nacional y de impulso de diálogo social. Los sectores que más han progresado en este diálogo social sectorial no han sido los tradicionalmente industriales o manufactureros (metal, química, etc.), sino otros sectores como agricultura, transporte construcción, telecomunicaciones, bancos, etc. Para 1998 se habían constituido estructuras de diálogo social sectorial en 18 sectores (Keller y Bansbach, en Marginson y Sisson, 2006). En el sector químico, el segundo sector europeo en términos de empleo (unos 2,5 millones de trabajadores), el primer acuerdo de creación del comité de diálogo social tuvo lugar a finales del 2004, siendo el comité sectorial número 31. La Federación Sindical Europea de Minas, Químicas y Energía (EMCEF, siglas en inglés), está compuesta por unos 130 sindicatos. La EMCEF ha empezado a trabajar en el tema de los CEEU desde el 2007, a partir del proceso de renovación de la Directiva. Un elemento clave para entender el diálogo sectorial europeo en la química es la amplitud de sectores que cubre la EMCEF, y el importante peso de la federación alemana del sector, el sindicato sectorial único IG BCE, en la EMCEF. Queda por observar si este diálogo sectorial ha servido para llegar a acuerdos en la aplicación de la nueva Directiva.

${ }^{6}$ Respecto al Comité de Empresa la Directiva de Sociedad Europea incluye desarrollos en cuestiones como los derechos de información, consulta y participación de los empleados, y en el papel asignado a la federación sindical europea en el mismo. Para Lecher, et al. (2002), esto supone un avance y clarificación de la Directiva 1994 de CEEU. 
En suma, para el análisis de los tres CEEU a analizar se propone por tanto un enfoque que presta atención a la interrelación entre tres dimensiones: a) los factores organizativos o internos al propio CEEU, y al grupo empresarial en donde las estrategias de gestión influyen en el funcionamiento del grupo y en el papel de las filiales; b) los factores institucionales o externos al grupo empresarial: los societales (relativos al país de origen de la EMN, y que afectan tanto a la organización del grupo como al funcionamiento de la representación sindical y de los empleados en la empresa) y los sectoriales (ya que cada sector tiende a operar bajo unas prácticas similares a la hora de organizar la relación entre la matriz y las filiales, la producción, etc.); y c) la dimensión europea: la regulación y la aplicación de la directiva europea de CEEU y el diálogo social sectorial al nivel de la UE son aspectos influyentes en la evolución de los tres CEEU a analizar.

\section{Las multinacionales químicas Alemanas en Tarragona}

El grupo Basf es el que presenta un perfil más alemán y europeo. Lane (2001) enfatiza su adhesión al principio de Verbundforschung (asociación de investigación) para la colaboración inter-organizativa a medio-largo plazo. A pesar del peligro de "des-naturalización" de toda estrategia de internacionalización, la I+D y los principales gestores han continuado proviniendo de Alemania. Según datos de la empresa para el 2007, Europa representa el $60 \%$ del volumen de negocio, y de sus casi 100.000 empleados en todo el mundo, aprox. el 64\% (61.000 empleados) están en Europa, de los cuales, 47.000 son de Alemania y aprox. 33.000 pertenecen a Basf Sociedad Europea. Esta distinción de Basf Alemania y Basf SE indica el equilibrio alemán-europeo que Basf está intentando desarrollar. Basf Española S.A. comenzó su actividad en Tarragona en el 1969 con una planta de poliestireno, y en los años 1990 instaló Tarragona su sede oficial de España. Basf España cuenta en 2008 con más de 2.500 trabajadores en todas sus empresas participadas, la mayor parte de ellos en Cataluña y de ellos unos 700 trabajadores en Tarragona.

El Grupo Bayer es una de las mayores empresas químicas mundiales, con más de 120.000 empleados en todo el mundo. Su internacionalización ha combinado la creciente dependencia de los mercados bursátiles internacionales con un control alemán del grupo desde su sede matriz. ${ }^{7}$ En España, Bayer llega en 1966, y lleva a cabo sucesivas inversiones productivas en la primera parte de los años 1970s. En el año 2005, la actividad de producción de plásticos ABS y SAN se escindió del Grupo Bayer constituyendo una nueva empresa independiente, Lanxess Styrenics,

${ }^{7}$ En su estructura accionarial del 2000, el 12-14\% de las acciones son de los empleados, y el $44 \%$ son de inversores de fuera de Alemania. Sin embargo, el Consejo de Dirección central de Bayer mantiene un alto nivel de control y de decisión; y en el Consejo de Supervisión hay una fuerte presencia de bancos alemanes (Lane, 2001). 
S.L. Bayer Iberia cuenta con unos 2.400 empleados, con sede en Barcelona. Actualmente, el Grupo Bayer en Tarragona está integrado por dos empresas: Bayer Polimeros que produce disocianatodifenilmetano, y Baysystems Iberia, S.L especializada en poliuretanos. La división de BaySystems en Tarragona es la más importante. BaySystems tenía en el 2008 a nivel mundial más de 4.000 empleados en 20 centros productivos, y en Tarragona unos 225 trabajadores.

El Grupo Clariant es líder europeo en los productos químicos especiales, con oficinas centrales en Muttenz, cerca de Basel (Suiza). En 1974 Hoeschst abre la planta de productos químicos especiales en Tarragona. En 1997, dentro del proceso de reestructuración del grupo alemán Hoeschst (por entonces uno de los mayores grupos químico-farmacéuticos del mundo), se vende la filial de Specialty Chemicals al grupo Clariant-Sandoz. Con el tiempo, el grupo Clariant se independiza y empieza su evolución y crecimiento como grupo empresarial. En la actualidad, Clariant tiene más de 100 empresas en los 5 continentes, y más de 20.000 empleados, organizadas en cuatro divisiones o especialidades. Clariant tiene la oficina central para la península ibérica en Barcelona. El centro de Tarragona ha sido crecientemente considerado como un centro competitivo dentro del grupo en Europa, y contaba en el 2008 con 150 empleados.

\section{El contexto del encuentro sindical y laboral aleman-español}

\subsection{El sistema español y catalán}

El sindicalismo español, aunque ha experimentado un proceso de cambio organizativo en los años 80s y 90s (Serrano del Rosal, 2000), presenta una serie de características estructurales. Köhler (2008) recoge tres rasgos principales: a) plurisindicalismo con varias confederaciones de diferente orientación ideológica; b) altos niveles de movilización, militancia y conflictividad, y bajos niveles de afiliación; c) bajo grado de regulación e institucionalización de las RRLL. Respecto a la representación de los empleados se pueden destacar tres características. En primer lugar, la representación de los empleados tiende a ser de vía doble, compartida entre la sección sindical y el comité de empresa, en un sistema general en el que la representación no es vía membresía, sino a través de una relativamente alta participación en las elecciones a comités de empresa. En segundo lugar, las dos federaciones sindicales más importantes, UGT (Unión General de Trabajadores) y CCOO (Comisiones Obreras), copan una amplia mayoría de los representantes en los comités de empresa (aprox. un 70-80\%), además de la presencia de las secciones sindicales en las empresas grandes y medianas. En tercer lugar, la estructura de los mercados laborales es altamente fragmentada. Existe una marcada diferencia entre los mercados laborales internos de trabajadores de cuello azul y blanco, que se reproduce en sus respectivos sindicalismos de clase y profesional. Asimismo, no hay vínculos sinérgicos entre los mercados laborales internos y los externos. A nivel de organización, hay algunas diferencias entre las dos confederaciones sindicales, que son más evidentes en el caso de Cataluña. Dentro de la CCOO, la federación catalana, desde 
su fundación inicial como $\mathrm{CNOC}$, ha desarrollado un perfil propio y con cierta autonomía; y durante muchos años ha superado a UGT en las elecciones a los comités de empresa. Las oficinas centrales de CCOO-Cataluña en Barcelona han acumulado recursos y capacidades de las que han dependido crecientemente muchas delegaciones provinciales y comarcales. Por su parte, UGT Cataluña no ha tenido una tradición de perfil propio, y ha tenido una mayor dependencia de la dirección central de la confederación, un marcado nivel de centralización que se observa también en lo que respecta a la delegación UGT de Tarragona respecto a Barcelona y Madrid. Se puede concluir que estas características debilitan al sistema sindical español a la hora de interactuar y negociar con las EMN.

\subsection{El sistema alemán}

En las RRLL alemanas se pueden destacar dos aspectos: la co-determinación y el gobierno corporativo, con diferencias según sector, y tipo y tamaño de empresa. En primer lugar, el sistema de co-determinación alemán está formalizado en el Consejo de Supervisión de representación paritaria entre la dirección y los empleados, que entre sus funciones está la de dar acceso a información estratégica y financiera de la empresa. El comité de empresa de los empleados elige a sus representantes al Consejo de Supervisión. En el proceso de internacionalización de las EMN alemanas este órgano y sistema de co-determinación ha servido para mantener un nivel de control sobre las decisiones estratégicas de la empresa. En segundo lugar, el sistema de gobierno corporativo alemán ha manifestado tradicionalmente una colaboración duradera entre empresas y bancos regionales y nacionales, enfatizando así un sistema de "insiders" a la situación financiera de la empresa, y un efecto de "dinero paciente". Lane $(1998,2001,2003)$ ha investigado cómo se ha transformado el gobierno corporativo y la estructura de propiedad dentro del proceso estratégico de internacionalización de las 3 grandes multinacionales químicas alemanas (Hoechst, Bayer y Basf), y concluye que estos tres grupos multinacionales han desarrollado estrategias de internacionalización diferentes, y por lo tanto han desarrollado diferentes grados de vinculación al sistema alemán de gobierno corporativo, de RRLL y de formación. Ambas dimensiones están interrelacionadas a través de la participación directa e indirecta de las instituciones financieras nacionales y regionales y de los sindicatos alemanes en los Consejos de Supervisión de muchas grandes empresas alemanas, y especialmente las del sector químico. En el sector de la química destaca el papel de la federación sindical (IG Chemie dentro del sindicato inter-sectorial IG BCE), tanto en su influencia sobre los comités de empresa, y por ende en los Consejos de Supervisión. ${ }^{8}$ Tal y como se recoge en varios informes del EIRO (European Industrial Relations Observatory) la federación sindical de la química tiene una larga tradición de colaboración con la asociación empresarial de

\footnotetext{
${ }^{8}$ Agradezco este comentario sobre la importancia de la federación sindical del sector químico a Holm-Detlev Khöler.
} 
la industria química alemana y con los equipos directivos de las grandes empresas químicas. ${ }^{9}$ Todo parece indicar que la existencia de dos órganos (Comité de Empresa y Consejo de Supervisión) ha legitimado que muchas empresas alemanas hayan optado por un modelo de CEEU de tipo francés, en el que hay representación de la Dirección.

\subsection{La recepción de la directiva CEEU por los sindicatos españoles}

Cuando se aprobó la directiva de los CCEU en 1994, la postura de UGT y de CCOO fue diferente. Para UGT, que históricamente había apostado por unas secciones sindicales fuertes, la Directiva optaba por un sistema en base a comités, y las secciones sindicales eran postergadas. CCOO lo recibió de manera más pragmática y posibilista. UGT argumentaba que la directiva se contradecía con la legislación española: la Ley Orgánica de Libertad Sindical de 1985 garantizaba la presencia sindical en la empresa y establecía el concepto de sindicato más representativo, factores que reforzaban a las grandes centrales sindicales frente a los comités de empresa y los sindicatos menores. Con el tiempo, las posturas convergieron. El sistema dual sindicatos-secciones y comités de empresa queda refrendado en la reforma del Estatuto de los Trabajadores en $1994 .^{10}$

España presenta una bajo nivel de creación e implantación de CEEU en las EMN españolas. En el 2000 la tasa de cobertura era de un $7 \%$ mientras que la media europea era aproximadamente de un 40\%. Según datos recogidos en Juan (2008), para el 2005 de 41 empresas españolas afectadas por la directiva solamente 4 tenían un CEEU, dando una tasa de cobertura de un 14,6\%, mientras la tasa en Europa había descendido a aproximadamente el $35 \%$. Según la base de datos especializada del CES (www.ewcdb.eu), en el 2010 solo hay 9 empresas españolas con CEEU. Paradójicamente, España es un país con una alta presencia de EMN extranjeras: con casi 1000 empresas filiales de EMN afectadas por la directiva, España ocupa el $4^{\circ}$. lugar de la UE con participación en CEEU, detrás de Alemania, Reino Unido y Francia, y por delante de Holanda, Bélgica e Italia. Por lo tanto, España tiene mucho en juego en los CEEU de las EMN afectadas por la Directiva. Todo un reto para el sindicalismo español.

A medida que las EMN iban ajustándose a la directiva y constituyeron CEEU los sindicatos españoles se enfrentaron a una serie de dilemas institucionales y organizativos. A nivel institucional, la relación entre UGT y CCOO vivió un hito importante en 1997 cuando UGT y CCOO decidieron aumentar su colaboración a través del concepto de acción concertada de cara a la negociación colectiva. En el 2000 las

${ }^{9}$ Ejemplo de esta colaboración es el acuerdo para la actualización de la nueva CEEU Directiva del 2008-2009, recogido en la segunda edición del 2010 de la http://www.ewcnews.com.

${ }^{10}$ El Estatuto de los Trabajadores es de 1980; la Ley Orgánica de Libertad Sindical en 1985 garantiza la presencia sindical en la empresa. 
EMN industriales en España y especialmente en Cataluña comenzaron un proceso de des-localización de la producción. En este mismo año 2000 UGT y CCOO llegaran a un acuerdo de colaboración sobre la representación en los CEEU. El acuerdo estipulaba que si el representante español era sólo 1, éste fuera del sindicato más votado: en caso de 2 representantes, éstos serían uno de cada sindicato; y en caso de 3, dos serían del sindicato más votado y el tercero del otro sindicato.

A nivel organizativo, hay algunas diferencias entre CCOO y UGT en Cataluña y Tarragona respecto al trabajo en los CEEU. CCOO Cataluña creó un secretariado internacional en la sede de Barcelona, dependiente de la secretaría general. Desde este secretariado y la Federación del Metal surgieron iniciativas de ayuda y de coordinación para los representantes en los CEEU. Cabe destacar el papel de algunos sindicalistas de la Federación del Metal, con experiencia directa en comités de empresa en EMN como SEAT-Wolkswagen o Tyco-Electronics, y que organizaron, hasta aproximadamente el 2007, un dinámico trabajo de coordinación, información, formación, etc. ${ }^{11}$ En CCOO Tarragona desde finales de los 90 ha habido una persona liberada para trabajar en los CEEU del sector químico de todo Cataluña. Sin embargo, esta persona liberada reconoce deficiencias, como el hecho de no haber tenido acceso a un conocimiento formalizado de las RRLL alemanas. Por su parte, en UGT de Cataluña, el único secretariado internacional ha estado en Madrid y las peculiaridades de los CEEU de Cataluña y de las empresas químicas de Tarragona han quedado un tanto diluidas en los intereses generales de los empleados de la industria y de la química española. Desde UGT Cataluña en Barcelona los servicios se han concentrado en la organización de cursos para los representantes en CEEU. A pesar de todo, UGT Tarragona ha logrado mantener su porcentaje de votos en las elecciones a comités en las EMN químicas, e incluso aumentar, como en el caso de Basf, en el que es el sindicato dominante desde el 2007, y en las elecciones del 2011 obtuvo 10 de los 17 miembros del comité de empresa.

Para el sindicalismo español, la participación en CEEU ha supuesto un difícil proceso de aprendizaje desde unas posiciones débiles y sin los apoyos organizativos necesarios para participar de forma efectiva (Köhler y González-Begega, 2007a). La participación en un CEEU requiere un proceso de formación, aprendizaje y apoyos internos y externos, un proceso que se ha considerado difícil incluso en el fuerte y bien organizado sindicalismo de los países nórdicos (Knudsen y Sorensen, 2000).

${ }^{11}$ Un ejemplo es el proyecto de Círculos de Estudio publicado el 2001: Comités de Empresa Europea: buenos ejemplos. 


\section{Creacion y evolucion de los CEEU}

\section{(1) Basf}

El CEEU de Basf se creó mediante el acuerdo voluntario sobre el procedimiento de información y consulta en 1994. La función principal de esta plataforma, Eurodiálogo, era coordinar las informaciones y los aspectos generales de las RRLL. El Eurodiálogo se componía de 25 miembros: 5 de Alemania ( 3 representantes de trabajadores, 1 directivo, y 1 de la federación sindical alemana de la química), y el resto se repartía de forma proporcional, tocándole a España 2 representantes $(1$ de CCOO y 1 de UGT). En el CEEU de Basf, los representantes españoles han encontrado una especie de choque cultural con el sistema alemán, fuente de desconfianza y de falta de entendimiento. Esta percepción aumentaba cuando los sindicalistas alemanes explicaban algunas de las decisiones del CEE como tradiciones sindicales alemanas. Así dice el representante español de CCOO que se les explicó la presencia de representantes de la dirección en el mismo, sin explicitar en qué consistía la práctica de la co-determinación. En este contexto, el representante de CCOO en el Eurodiálogo de Basf enfatiza el fuerte carácter alemán del mismo, en el que la dirección y el comité de empresa alemán han tenido su propia línea de comunicación en paralelo. El representante español, de CCOO desde su creación hasta el 2007, crítica también el excesivo uso de la confidencialidad en los procesos de información, y su estrategia ha sido crear alianzas con los representantes del Sur de Europa, para llevar al Eurodiálogo propuestas trabajadas y con apoyo.

En el 2007 Basf decidió transformarse en Sociedad Europea (SE), y Eurodiálogo ha pasado a convertirse un comité de empresa. ${ }^{12}$ El acuerdo de constitución y los estatutos del nuevo comité de empresa satisfacen algunas de las expectativas del nuevo representante español en el CEE de Basf, de UGT. La composición del nuevo comité es de 23 miembros, de los que 8 corresponden a Alemania. Asimismo los 6 representantes de trabajadores en el Consejo de Supervisión paritario son: 3 alemanes (según cuadros), 1 belga, y 2 de federaciones sindicales (alemana y europea). El representante de UGT reconoce las nuevas posibilidades que se abren para una mayor tarea sindical en Basf al nivel europeo, pero sospecha que el trabajo sindical en un CEEU de una EMN alemana siempre conlleva un plus de complejidad y dificultad, dado el fuerte y rígido peso de las normas y reglas de los estatutos y las leyes a las que se adscribe.

${ }^{12}$ En el Instituto de Investigación de la CES (ETUI) el acuerdo de Comité de Empresa de Basf SE fue recibido de forma positiva, tal y como se encabeza el boletín informativo sobre CEEU del ETUI: This marks the most significant step forward so far towards broad, compulsory worker participation in a European company, through the BASF European Works Council and worker representation on the company's supervisory board (http://www.ewc-news.com) 


\section{(2) Bayer}

En 1991 se crea el Europa-Forum de Bayer en un acuerdo entre el comité de empresa y la dirección de la empresa alemana Bayer AG, según el modelo voluntario anterior a la primera directiva. ${ }^{13} \mathrm{El}$ acuerdo afectaba a todas las filiales del grupo Bayer en Bélgica, Reino Unido, Francia, Italia y España. En Octubre de 1994, con la nueva directiva aprobada, este acuerdo original fue sustituido por un acuerdo general de grupo. Por lo tanto, el CEEU Bayer se creó como resultado de un acuerdo entre la dirección y el sindicato alemán. El acuerdo favorece una alta presencia alemana en su composición, excluye a Alemania (Bayer AG) de las cuotas de representación, y otorga a la dirección de la empresa aproximadamente $1 / 3$ parte en el CEEU. Como resultado, aprox. el $45 \%$ por ciento de la representación es alemana. Por parte de España ha habido siempre 2 representantes, uno de Tarragona, que ha sido hasta la fecha el representante de UGT. El CEEU de Bayer ha tenido un cierto pero lento proceso de formalización y clarificación de tareas y funciones entre los diferentes cargos. Ha llevado a cabo un acercamiento a los sindicatos, tanto alemanes, como a la federación sindical europea. En general ha servido como un órgano para compartir información y cierto nivel de consulta. El representante de Tarragona-UGT enfatiza la necesidad de mejorar los mecanismos de información y consulta, así como el aumento del número de reuniones y el papel de expertos. La alta confidencialidad es también considerada un problema, dado el acceso del comité y del sindicato alemán a información relevante a través del Consejo de Supervisión. En el 2009 Bayer ha renegociado su acuerdo de CEEU para adaptarse a la nueva directiva.

El CEEU se puso a prueba durante el proceso de integración de la empresa Lanxess que el Grupo Bayer adquirió en 2005. La integración de Lanxess, de unos 100 empleados, en Bayer suponía una reestructuración del negocio del grupo de polímeros. El cierre de alguna planta parecía una decisión necesaria, y desde la dirección se valoró el cierre de la planta de Tarragona ó de Dormagen en Alemania, y concentrar la producción en la otra. La mala situación económica de la empresa de Tarragona la hacía candidata al cierre. El comité de empresa español reaccionó y usó el CEEU para tener acceso a la información relevante sobre la decisión de reestructuración. Los representantes españoles e italianos propusieron que el CEEU fuera el órgano de la negociación de la reestructuración, y alcanzaron un acuerdo en el CEEU para que el tema se negociara a través del propio CEEU. Según la versión del representante español, el sindicato alemán desarrolló en paralelo su propia negociación con la dirección, justificándolo en base a tradiciones alemanas como la co-determinación, etc. Por un tiempo, la tensión se apoderó del CEEU. Al final, ninguna de las dos fábricas cerró y tras superar el susto y la tensión, la reflexión en

${ }^{13}$ El comité de empresa de Bayer ha sido pionero en promover la dimensión internacional, a través de World Work Councils (Rüb, 2002), especialmente en lo que se refiere a las filiales del grupo en América Latina. 
el CEEU llevó a reconocer de forma mayoritaria que el CEEU tiene la capacidad de representar y negociar con la empresa los intereses de los empleados a nivel europeo. Así lo reconoce el representante español, que aún reconociendo el corto desarrollo y contenido del CEEU, lo valora de forma positiva y prefiere centrarse en el desarrollo de sus potencialidades.

\section{(3) Clariant}

En 1996 el grupo Clariant-Sandoz creó por acuerdo voluntario un CEEU para la información y consulta de los trabajadores en Europa. Una vez segregada de Hoescht en 1999, el Grupo Clariant pasó su sede oficial a Suiza, pero para temas legales de la UE se rige por la legislación de Bélgica. En el CEEU de Clariant han tenido lugar varias transformaciones, especialmente en su funcionamiento. Desde 1999 el CEEU está compuesto por 20 delegados: 7 de Alemania y Austria, 2 de Suiza, 2 de Italia, 3 de Francia, 2 del Reino Unido, 1 de Bélgica, 1 de los países escandinavos, y 2 de España (y Portugal hasta el 2001). En el 2007 se renegoció el acuerdo del CEEU. En el 2010 Clariant ha adquirido el estatuto de Sociedad Europea, y por lo tanto ha renegociado su acuerdo de comité de empresa, que no se incluye en este análisis.

Hay varias dinámicas de cambio en el CEEU de Clariant desde 1996 hasta al 2007. Primero, el número de delegados de los empleados: en 1997 se optó por 12 delegados, pero el sistema de elección fue criticado y tras 2 años de negociaciones en el grupo Clariant y Hoescht, se pasó a 20 delegados en 1999. Segundo, la composición y forma de elección de los miembros del CEEU. El acuerdo establece un especial estatus al Presidente y al Vicepresidente del CEEU: el Presidente es elegido por la dirección de la empresa y el Vicepresidente por los empleados. La elección del Presidente por la empresa ha sido utilizada como tema e instrumento de negociación, para demandar incrementos en el presupuesto del CEEU. Tercero, el CEEU ha tenido un desarrollo organizativo interno. Se acordó la creación de un Comité Restringido, compuesto por 4 personas (un presidente que es el Vicepresidente del CEEU, y 3 representantes elegidos por los 20 delegados), que se reúne como mínimo unas 2 veces al año. Asimismo, ha aumentado las actividades. Por ejemplo, han crecido el número de reuniones por año (en el 2007 se celebraron 3 reuniones extraordinarias, además de la única ordinaria que estipula el acuerdo de CEEU), y las reuniones han pasado de durar el día y medio estipulado en el acuerdo CEEU a casi 4 días en los últimos años. En este proceso de evolución el representante de CCOO de España ha ocupado el cargo de Vicepresidente desde el 2002, sin ser España un país con un alto número de empleados y delegados. Las habilidades individuales del representante de $\mathrm{CCOO}$ y los recursos organizativos desarrollados por su sindicato al nivel catalán le han permitido llegar a ocupar este cargo, y así posicionar y defender los intereses de los empleados de la filial española en el CEEU. Paradójicamente, el representante español abandonó la empresa en el 2010, y el puesto de Vice-presidencia no ha sido ocupado por un representante español. 


\section{Análisis}

Los factores externos explican mayormente los aspectos comunes de los tres CEEU. La similitud es más observable en el funcionamiento de los CEEU de Bayer y de Basf, que han seguido una evolución similar en la creación y gestión del CEEU. El factor país es un factor clave. En la variable de país receptor se puede destacar el impulso dado desde los acuerdos del 2000 de colaboración UGT-CCOO en CEEU para superar la debilidad estructural del sistema laboral español y para afrontar el difícil reto de la negociación con actores globales y poderosos. Por su parte, en el factor de país de origen destaca el fuerte carácter alemán de los CEEU. Además de una clara mayoría de representantes alemanes, algunas prácticas de funcionamiento indican un cierto cierre grupal (closure), por ejemplo, en la justificación tanto del modelo de organización co-participativo del CEEU, como el flujo selectivo de información y la confidencialidad por parte de los representantes alemanes, un cierre grupal también recogido por la investigación cualitativa de Biknell (2007). Otro aspecto común viene del factor sector productivo. El hecho que la producción química realiza una buena parte de sus procesos de forma interna lleva a una débil interacción productiva con sus entornos cercanos. Este factor ha llevado a los representantes sindicales locales en las filiales de las EMN, aún disfrutando de un alto estatus en el contexto sindical y laboral local, a una posición de cierto aislamiento, en comparación por ejemplo con otros CEEU en sectores como la automoción, electrónica, etc., con mayores cadenas de valor.

Los factores internos, tanto del CEEU como del grupo empresarial, explicarían la diferenciación de cada CEEU. El de mayor desarrollo formal y sustantivo ha sido el CEEU de Clariant, el cual se podría acercar al tipo eurocéntrico propuesto por Biknell. El CEEU de Basf (convertida en sociedad europea en el 2007, con un CEEU formalmente reformulado), parece haber abierto una nueva etapa, que coincide con una cambio en la representación española, UGT desde el 2007. Al convertirse en SE, es de esperar que el CEEU avance claramente hacia rasgos del tipo eurocéntrico. En el caso del CEEU de Bayer, y debido quizá a su estrategia de mayor internacionalización global, el foro de diálogo no ha experimentado avances sustantivos. De cualquier manera, el éxito del la integración de Lanxess en el grupo Bayer sin cierres ni despidos parece haber estimulado a una nueva etapa de mayor confianza entre los representantes nacionales. Sin embargo, su CEEU de Bayer parece situarse todavía en características del CEEU policéntrico.

En una perspectiva evolutiva general, los CEEU analizados han evolucionado a lo largo de los cuatro estadios de ciclo vital desarrollados por Lecher, et al. (2001): simbólico, instrumento de información y comunicación, proyecto orientado, y europeo. En los tres casos se puede considerar que han dejado atrás la fase simbólica inicial para avanzar en la fase de instrumento de información y comunicación, e iniciarse en la fase de proyecto orientado, que en caso de la BASF, debido especialmente a su estatus de Sociedad Europea, bien podría indicar el inicio de su estadio de europeización sustantiva. Al inicio del proceso a mediados de los años 90 los representantes sindicales españoles se encontraban en una situación de debilidad 
organizativa y asimetría institucional, es decir, con falta de recursos y capacidades organizativas, y con un sistema institucional débil para el arduo trabajo sindical y de representación laboral en EMN. A medida que han ido surgiendo problemas comunes, los actores sindicales han ido adoptando cambios tanto a nivel institucional como organizacional para una mejor coordinación y a veces cooperación en el trabajo en los CEEU. Entre estos avances se puede destacar el acuerdo de representación en CEEU del 2000 entre CCOO y UGT, o las dinámicas de información y coordinación desarrolladas por la Secretaria Internacional y la Federación del Metal de CCOO de Cataluña. En lo que respecta a los representantes de las filiales españolas en los tres CEEU analizados la marcada asimetría estructural inicial ha ido evolucionando hacia unas dinámicas más interactivas y de aprendizaje entre los miembros del CEEU, especialmente en el caso de Clariant, en el de Bayer durante la crisis de Lanxess, y en el nuevo CEEU de Basf una vez constituida como Sociedad Europea. Sin embargo, el aprendizaje ha sido corto y queda un largo camino para llegar a unas relaciones más simétricas en los CEEU analizados.

En síntesis, es la específica combinación de factores externos e internos que tienen lugar en torno a un CEEU lo que mueve la evolución sustantiva hacia un CEEU más participativo y europeo. La conversión de una EMN en una Sociedad Europea (SE), como es el caso de Basf, es un elemento importante en la europeización de un CEEU. En ese sentido, en la medida en que muchas EMN alemanas por factores institucionales empresariales y sindicales de ese país se conviertan en SE, sus CEEU respectivos podrían avanzar hacia la europeización de la representación de los empleados. Asimismo, factores externos pueden influir en la forma en que la nueva Directiva de CEEU es aplicada en los países y en las propias EMN, tal y como se ha visto en el caso del acuerdo de aplicación de la nueva directiva CEEU en Alemania por parte de la federación sindical y la patronal del sector. Es decir, factores externos nacionales o sectoriales pueden influir en que los nuevos CEEU tengan o no un mayor contenido y función. Por lo tanto, es una cuestión importante a investigar la relación entre factores externos y externos en las nuevas dinámicas de europeización de las RRLL a través de los CEEU, dentro de los recientes desarrollos regulativos, especialmente la Directiva de la Sociedad Europea del 2001, y de la nueva Directiva de CEEU del 2008-09.

\section{Conclusiones}

El artículo ha analizado la influencia de varios factores internos y externos en la creación y evolución de los CEEU de tres EMN químicas alemanas en el complejo de Tarragona. La directiva de la UE de los CEEU es una regulación blanda, que implica una negociación continua, y por tanto estimula las posibilidades de aprendizaje y evolución. Los tres CEEU analizados son casos representativos, importantes y singulares.

En el análisis se han identificado las dinámicas comunes y diferentes de los tres CEEU dentro del contexto regulativo de la UE. Las dinámicas similares han sido 
influidas por los factores externos. El país de origen de las EMN es Alemania, y esto ha marcado el funcionamiento y parte de la evolución de los CEEU. Los tres CEEU se crearon dentro de un contexto de colaboración sindical-patronal en Alemania, reflejado en la constitución de CEEU co-participados con la dirección, siguiendo el modelo francés, pero legitimado por la tradición de co-determinación alemana. Por lo que atañe al factor país de la filial, en los tres CEEU destaca el papel de los representantes de la federación sindical COOO-Cataluña, la cual ha destacado por una mayor pro-actividad en el trabajo sindical en los CEEU de las EMN industriales. Finalmente, sobre la variable sector hay que destacar: a) el alto grado de integración vertical interna de las filiales en la estructura de las EMN, lo cual ha hecho que sus CEEU tengan poca vinculación con el contexto local; y b) una alta concentración empresarial en un número reducido de grandes empresas en Europa, lo cual suele estimular procesos de monitorización y vigilancia con un ciertos efectos isomórficos. Las dinámicas diferenciadoras se han debido a los factores internos. BASF se ha convertido en Sociedad Europea en el 2007 y parece haber iniciado el estadio de europeización en la evolución de su CEEU. Bayer ha desarrollado un perfil más internacional, y su CEEU ha mantenido una evolución más lenta. Clariant se creó en 1997 como empresa independiente, y el hecho de ser una empresa de menor tamaño y autónoma ha impulsado dinámicas de negociación y evolución en su CEEU.

La participación de los representantes de trabajadores de Tarragona en los CEEU de las tres EMN químicas alemanas ha evolucionado desde una alta asimetría estructural inicial ante unos fuertes actores globales, hacia una relación más dinámica con posibilidades de relación más equilibrada, y con caminos cada vez más diferenciados. Al inicio del proceso los representantes españoles se encontraban en una situación de debilidad organizativa e institucional por los rasgos del sistema laboral y sindical español. A lo largo del proceso los actores sindicales han ido generando recursos organizativos y prácticas de colaboración para mejorar el trabajo sindical y de representación en estos CEEU. Esta cierta mejora se puede observar en el papel de los representantes españoles, por ejemplo, en el CEEU de Clariant donde alcanzó una Vicepresidencia, y en la actuación durante la crisis de Lanxess en el grupo Bayer.

Finalmente se puede extender la reflexión al sistema laboral español, y hacer alguna sugerencia. El sindicalismo español se encuentra ante retos importantes para hacer frente a la globalización económica y productiva, y la glocalización de las relaciones laborales. Una cuestión crítica es la debilidad de las organizaciones sindicales locales para hacer frente a las estrategias globales de las EMN. En base a lo analizado en los tres CEEU, una posible solución seria una mayor capacitación y descentralización organizativa funcional a las secciones provinciales y locales, en un sistema de mayor coordinación multi-nivel y de mejor colaboración intersindical. A nivel general resulta importante impulsar el nivel y la amplitud de la reflexión por parte de los diferentes actores políticos y sociales sobre la globalización económica y sus efectos en las relaciones laborales. Los CEEU son casos relevantes que pueden orientar el debate y la reflexión. 


\section{Bibliografía}

Bean, R. (1994). Comparative industrial relations. An introduction to crossnational perspectives. London: International Thomson Business Press.

Bicknell, H. (2007). Ethno, Poly- and Eurocentric EWCs. En Whittall, M., Knudsen, H., y Huijgen, F. (eds.), Towards a European Labour Identity. The case of the European Work Council (pp 111-131). Londres/N.Y: Routledge.

EIRO (European Industrial Relations Observatory) (2004). European Work Councils in practice. Dublin: Eurofound.

Fitzegerald, I. y Stirling, J. (2004). European works councils: pessimism of the intellect, optimism of the will?. Londres: Routldege.

Hollingsworth, J.H. y Streeck, W. (eds) (1994). Governing capitalist economies: performance and control of economic sectors. New York: Oxford University Press.

Juan Albacete, J. (2008). La implantación de los Comités de Empresa Europeos en España. Revista Española de Investigaciones Sociológicas. 124, 177-207.

Keller, B. (2003). Social dialogues at sectoral level: the neglected ingredient of European Industrial Relations. En Keller, B. y Platzer, H-W. (eds) Industrial Relations and European Integration (pp: 30-57). London: Ashgate.

Kerckhofs, P. (2002). European Work Councils: facts and figures. Bruselas: European Trade Union Institute.

Kristensen, P. H. y Zeitlin, J. (2005). Local players in global games. The strategic constitution of a multinational corporation. Oxford: Oxford University Press.

Knudsen, H. y Sorensen, O. R. (2000). Multinationale lonmodtagere: erfaringer med europaeiske samarbejdesudvalg. Aalborg: Aalborg Universitetsforlag.

Köhler, H-D. (2008). Los sindicatos en España frente a los retos de la globalización y del cambio tecnológico. Documento de Trabajo 142-2008. Madrid: Fundación Alternativas.

Köhler, H-D. y González-Begega, S. (2003). ¿Hacia un sistema de relaciones industriales europeo?. La experiencia de los Comités de Empresa Europeos (CEUs). Cuadernos de Relaciones Laborales. Vol. 22 Núm. 1, 7-36.

Köhler, H-D. y González-Begega, S. (2007a). Still learning from Europe: Spanish participation in European works councils. En Whittall, M., Knudsen, H., y 
Huijgen, F. (eds.) Towards a European Labour Identity. The case of the European Work Council (pp 132-150). Londres/N.Y: Routledge.

Köhler, H-D. y González-Begega, S. (2007.b). Diálogo Social y negociación colectiva a escala sectorial en la Unión Europea. Limitaciones y perspectivas. Cuadernos de Relaciones Laborales. 25 (2), 117-49.

Lane, C. (1998). European Companies between globalization and localization: a comparison of internationalization strategies of British and German MNCs. Economy and Society. 27 (4), 62-485.

Lane, C. (2001). The emergence of German Transnational Companies: a theoretical analysis and empirical study of the globalization process. En Morgan, G. Kristensen, P.H., y Whitley, R. (eds) The Multinational Firm. Organizing across institutional and national divides (pp. 69-96). Oxford: Oxford University Press.

Lane, C. (2003). Changes in corporate governance of German corporations: Convergence to the Anglo-American Model?, ESRC University of Cambridge Centre for Business Research, Working Paper No. 259.

Lecher, W., Platzer, H-W, Rüb, S. y Weiner, K-P. (2001). European Work Councils: developments, types, networking. Aldershot: Gower.

Lecher, W., Platzer, H-W, Rüb, S. y Weiner, K-P. (2002). European Work Councils: Negotiated Europeanization. Between statutory framework and social dynamics. London: Asghate.

Marginson, P. y Sisson, K. (2006). European Industrial Relations. Multi-level governance in the making. London: Palgrave.

Poole, M. (1986). Industrial Relations: origins and patterns of national diversity. London: Routledge \&Kegan Paul Ltd.

Purcalla, M. A., Belzunegui, A., Moreno, J., Pastor, I, y Romero, A. M. (2010). Empleo, organización empresarial y tecnología. Análisis aplicado en el sector químico. Valencia: Tirant Lo Blanch.

Ruyssevedt, J. V., y Huiskamp, R. (eds) (1995). Comparative industrial and employment relations. London: Sage.

Rüb, S. (2002). World Works Councils and Other Forms of Global Employee Representation in Transnational Undertakings. A survey. Arbeitspapier 55. 
Serrano del Rosal, R. (2000). Transformación y cambio del sindicalismo español contemporáneo. Madrid: CSIC.

Waddington, J. (2011). European Works Councils and Industrial Relations: A Transnational Industrial Relations Institution in the Making. Oxon: Taylor \& Francis.

Waddington, J. y Kerckhofs, P. (2003). European Work Councils: what is the current state of play. Transfer. Vol. 9, 322-339.

Whittall, M., Knudsen, J. y Huijgen, F. (eds) (2007). Towards a European Labour Identity. The case of the European Work Council. Londres/NY: Routledge.

Wills, J. (2000). Great expectations: Three years in the life of a European Work Council, European Journal of Industrial Relations. 6, 85-108. 